\title{
Should the chronic form of tularemia be defined? Should the treatment of
}

\section{the chronic form be managed differently?}

\author{
Yesim Alpay ${ }^{1 *}$
}

\begin{abstract}
Background: Tularemia is a bacterial, zoonotic disease caused by Francisella tularensis. Although the ulceroglandular form is the most common form in the world, oropharyngeal tularemia is the most common form in Turkey. Lymph node suppuration is the most common complication. F. tularensis causes granulomatous and suppurative lesions in the lymph nodes and other organs.
\end{abstract}

Methods: Seventeen suspected oropharyngeal form tularemia cases complicated with suppurated lymphadenitis have been examined in this study. All of the patients $(17,100 \%)$ had cervical lymphadenopathies and had a history of beta-lactam antibiotic use with the diagnosis of tonsillitis. Tularemia cases were diagnosed according to the case definition of World Health Organization (WHO).

Results: All of the patients $(17,100 \%)$ had cervical lymphadenopathies ranging in size from 2-8 $\mathrm{cm}$ and unilateral lymphadenopathy, while $12(71 \%)$ patients had right-sided lymphadenopathy. The rate of fever was $41 \%$ and the rate of pharyngitis or tonsillitis was $52 \%$ at presentation. All patients had a history of beta-lactam antibiotic use with the diagnosis of tonsillitis. Seven patients recovered with first-line monotherapy. In the remaining 10 patients, treatment was rearranged, and these patients were switched to combination treatment or another anti-infective. Surgical drainage was performed on all but two of the patients.

Conclusions: The diagnosis of tularemia is often delayed. It may take a significant length of time to diagnose the condition and the disease may become complicated. As it is understood from our study and other studies, the types and duration of treatment can vary and differences can be observed in cases that are past the acute stage. Although the guideline has included a classical treatment approach for the tularemia, there is no standard approach to cases with delayed diagnosis, complicated cases and those refractory to conventional regimens. These observations and other examinations have raised the question whether the chronic form of tularemia should be defined, and whether the treatment options and durations should be re-standardized according to the 'chronic tularemia' definition as a 'chronic granulomatous disease'.

Keywords: Tularemia, Orofarengeal Form, Chronic, Granulomatous infection, Treatment

\section{Introduction}

Tularemia is a bacterial, zoonotic disease, especially seen in the northern hemisphere (1). However, in recent years, tularemia cases have been reported from Turkey, Yugoslavia, Spain, Kosovo, and Switzerland (2). Turkey represents $13 \%$ of the reported cases of tularemia in Europe between the years 1992 and 2012 (3). In recent years, outbreaks that are particularly associated with water have been observed in Turkey. $F$. tularensis is a bacteria that is highly resistant to environmental conditions and the ability of $F$. tularensis to survive in free-living water amoeba (Acanthamoeba castellani) is considered to be important for the regional persistence of the disease and in the waterborne epidemics (4).
F. tularensis is transmitted to humans via dermal, oral, conjunctival or respiratory routes by direct contact with infected animals, ingesting contaminated food or water, inhalation of contaminated aerosols, or arthropod bites (5).

F. tularensis causes granulomatous and suppurative lesions in the lymph nodes and other organs (6).

The bacterium locally replicates at the entry site from where it spreads to the regional lymph nodes. Since it is a facultative intracellular microorganism, it can continue to replicate inside endothelial cells and macrophages (7).

Received 22-03-2018 Accepted 27-03-2018 Available Online 31-03-2018 
Rapid proliferation of the bacterium in lymphoid tissues causes follicular hyperplasia leading to focal suppurative necrosis, which in turn results in the formation of granulomas. Histopathologically, it is characterized by characterized by granulomatous lesions containing focal caseous and necrotic areas. Differential diagnosis should include infectious and non-infectious causes due to the development of granulomatous and suppurative lymphadenitis. Granulomatous lymphadenitis is often confused with tuberculosis $(2,4,6,8)$.

There are six main clinical forms of tularemia: ulceroglandular, glandular, oculoglandular, oropharyngeal, typhoidal, and pneumonic forms (6). Although the ulceroglandular form of the disease is the most common form in the world, oropharyngeal tularemia is the most common form in Turkey. This clinical form involves direct invasion of oropharynx by the bacteria. It is transmitted by the consumption of contaminated water and food. Lymph node suppuration is the most common complication (9).

Oropharyngeal tularemia may be easily confused with other diseases affecting the cervical lymph nodes, such as streptococcal tonsillitis, tuberculosis, infectious mononucleosis and lymphoma (10).

The majority of the patients have a history of tonsillopharyngitis prior to beta-lactam antibiotic use and unresponsiveness to treatment. It may take a significant length of time to diagnose the condition and the disease may become complicated. Delays in the use of the appropriate antibiotics result in failure to respond to treatment.

Oropharyngeal form tularemia cases complicated with suppurated lymphadenitis have been examined in this study.

\section{Material and Method}

Seventeen suspected tularemia cases were admitted to the Department of Infectious Diseases and Clinical Microbiology at Balıkesir University Faculty of Medicine between January 2015 and September 2017. The data were retrospectively retrieved from the medical records. Data included demographic characteristics of the patients, history of illness, symptoms, clinical findings, laboratory test results, treatment characteristics and therapeutic responses. Detailed information about patient's occupation, the site of infection, day of onset, insect bites, contact with animals, living in rural areas, clinical symptoms, and so on was obtained using an applied questionnaire. Tularemia cases were diagnosed according to the case definition of World Health Organization, suspected tularemia case was defined as the presence of fever, membranous pharyngitis or tonsillitis and cervical lymphadenopathy. Suspected cases may be coming from the epidemic region and unresponsive to beta-lactam antibiotics. Suspected case with a positive serological laboratory result (serological titer $\geq 1 / 160$ for micro-agglutination test) and positive polymerase chain reaction (PCR) for $F$. tularensis was considered to be diagnosed with disease (6).

Blood samples were collected from patients having clinical findings consistent with tularemia. Serum samples were separated and sent to National Central Laboratory, where the micro-agglutination test was used for serological diagnosis. Confirmed tularemia cases were patients with compatible clinical findings and with positive serological titer (titer $\geq 160$ for MAT). Brucella, salmonella, toxoplasma serology, rubella, Epstein-barr virus, cytomegalovirus, hepatitis $\mathrm{A} / \mathrm{B} / \mathrm{C}, \mathrm{HIV}$ serologic tests, PCR and bacterial culture of tuberculosis (lymph node drainage material) tests were requested for differential diagnosis.

\section{Results}

Seventeen tularemia cases were included in the study; demographic characteristics, clinical and laboratory findings, and treatments were evaluated. The mean age of the patients was $47(18-76) ; 12(71 \%)$ were female and $5(29 \%)$ were male. All patients were rural inhabitants living in endemic regions, using tap water and in contact with animals. All patients had oropharyngeal form of tularemia complicated with suppurated lymphadenitis. Ulcerative skin lesions were not found in any patient.

All of the patients were patients with treatment experience who had previously applied to a health facility more than once. The average time from disease onset to admission to our clinic was 113 days (20-220). All of the patients $(17,100 \%)$ had cervical lymphadenopathies ranging in size from $2-8 \mathrm{~cm}$. All patients had unilateral lymphadenopathy, while 12 (71\%) patients had right-sided lymphadenopathy. Two patients had preauricular lymphadenopathy in addition to cervical lymphadenopathy. Patients with large lesion size had painful and limited neck movements. In the medical history of the patients, it was found that all patients had symptoms such as fever, tremor, myalgia, sore throat, and fatigue during the onset of the disease. The rate of fever was $41 \%$ and the rate of pharyngitis or tonsillitis was $52 \%$ at presentation. All patients had a history of beta-lactam antibiotic use with the diagnosis of tonsillitis. Demographic data, clinical and laboratory findings are presented in table1. Seven patients recovered with first-line monotherapy. In the remaining 10 patients, treatment was rearranged, and these patients were switched to combination treatment or another anti-infective. One patient was unresponsive to four-week course of therapy, and response was achieved after the patient was switched to third-line therapy. No treatment failure was observed in patients who used quinolone in monotherapy or combinations. Surgical drainage was performed on all but two of the patients. Details of the treatments are given in table 2 . 
Table 1: Demographic data, clinical and laboratory findings of Tularemia patients

\begin{tabular}{|c|c|}
\hline Age (Mean) years & $47(18-76)$ \\
\hline Gender & $12(71 \%)$ female, $5(29 \%)$ male \\
\hline Living in rural areas, $\mathrm{n}(\%)$ & $100 \%$ \\
\hline Onset of symptoms (days) & 113 days (20-220 days) \\
\hline Fever, n (\%) & $41 \%$ \\
\hline Sore throat, $\mathrm{n}(\%)$ & $52 \%$ \\
\hline Lymphadenopathy, n (\%) & $17(100 \%)$ \\
\hline $\mathrm{WBC}\left(\mathrm{mm}^{3}\right)$ & $9500(5300-13500)$ \\
\hline ESR (mm/hr) & $27(4-74)$ \\
\hline $\mathrm{CRP}(\mathrm{mg} / \mathrm{L})$ & $18(3-49)$ \\
\hline AST (U/L) & $19(13-24)$ \\
\hline ALT (U/L) & $20(6-47)$ \\
\hline Tularemia micro-agglutination test titers (range) & $1 / 160-1 / 1280$ \\
\hline Brucella Agglutination test positivity & None \\
\hline Salmonella Agglutination test positivity & None \\
\hline Positive serology of Toxoplasmosis & None \\
\hline Positive serology of Rubella & None \\
\hline Positive serology of Epstein Barr virus & None \\
\hline Cytomegalovirus positivity & None \\
\hline Hepatitis A/B/C, HIV positivity & None \\
\hline Bacterial culture ( lymph node drainage material) & None \\
\hline Tuberculosis PCR (lymph node drainage material) (positivity) & None \\
\hline
\end{tabular}

Table 2: Treatment management of cases

\begin{tabular}{|c|l|c|c|c|}
\hline Case & \multicolumn{1}{|c|}{$\begin{array}{c}\text { First-line Therapy } \\
\text { (2 weeks) }\end{array}$} & $\begin{array}{c}\text { Second-line Therapy } \\
\text { (2 weeks) }\end{array}$ & $\begin{array}{c}\text { Third-line Therapy } \\
\text { (2 weeks) }\end{array}$ & Drainage \\
\hline $\mathbf{1}$ & Streptomycin+doxycycline & Doxycycline+ciprofloxacin & - & + \\
\hline $\mathbf{2}$ & Doxycycline & Streptomycin & Ciprofloxacin+gentamicin & + \\
\hline $\mathbf{3}$ & Streptomycin & Doxycycline+ciprofloxacin & - & - \\
\hline $\mathbf{4}$ & Doxycycline & - & - & + \\
\hline $\mathbf{5}$ & Streptomycin+doxycycline & - & - & + \\
\hline $\mathbf{6}$ & Streptomycin & - & - & + \\
\hline $\mathbf{7}$ & Doxycycline & Ciprofloxacin & - & + \\
\hline $\mathbf{8}$ & Doxycycline+ciprofloxacin & - & - & + \\
\hline $\mathbf{9}$ & Doxycycline & Ciprofloxacin & - & + \\
\hline $\mathbf{1 0}$ & Doxycycline & Doxycycline+ciprofloxacin & - & + \\
\hline $\mathbf{1 1}$ & Doxycycline & - & - & + \\
\hline $\mathbf{1 2}$ & Ciprofloxacin & - & - & + \\
\hline $\mathbf{1 3}$ & Streptomycin & - & - & + \\
\hline $\mathbf{1 4}$ & Doxycycline & Doxycycline+ciprofloxacin & - & + \\
\hline $\mathbf{1 5}$ & Doxycycline & Doxycycline+ciprofloxacin & - & + \\
\hline $\mathbf{1 6}$ & Doxycycline & - & - & + \\
\hline $\mathbf{1 7}$ & Doxycycline & - & - & + \\
\hline
\end{tabular}




\section{Discussion}

In Tularemia cases, the severity of the disease can range from asymptomatic or mild disease to rapidly progressive and fatal clinical course, depending on the bacterial virulence, the mode of entry to the host, the number of inocula, and the immunological status of the host $(8,9,11)$. The clinical picture is characterized by sudden-onset high fever, tremor, headache, fatigue, myalgia, and arthralgia. Fever is usually present in the early phase of the disease and may not be present in patients presenting in the late term (12).

The majority of the cases in this study were patients who presented to our clinic during the later stages of the disease, with unresponsiveness to previous antibiotherapy. At the time of admission, only 7 (41\%) patients had fever. In these cases, fever was accompanied by fatigue, myalgia, sore throat, and headache. Swelling in the neck was observed in all cases. The most common complaints in cases of oropharyngeal tularemia are swelling in the neck, sore throat, and fever. In cases occurring in Turkey, swelling in the neck is observed at a rate of $92-100 \%$, fever is observed at a rate of $66-90 \%$, and sore throat is observed at a rate of $58-92 \%(13,14,15,16)$. In a multi-center study conducted in Turkey, oropharyngeal form of tularemia was observed in $85.3 \%$ of the cases. Lymphadenopathy was observed in $95 \%$, fever in $85 \%$, sore throat in $84 \%$, and headache in $4 \%$ of the cases, and the mean time to admission was 21 days (1-135) (17). In our cases, the mean duration of disease was 113 days (20-220). This was due to the fact that the patients in this study were previously monitored and treated in primary and secondary healthcare services, but referred to tertiary healthcare services due to unresponsiveness to treatment.

In our cases, lymphadenopathy was localized to the right cervical region in $71 \%$ of the cases. There was no bilateral involvement. In the study by Tezer et al. (18), right lymphadenopathy was observed in 11 out of 16 cases $(68.7 \%)$, and in the study of Şencan et al., cervical lymphadenopathy was observed in the left side in $66.7 \%$ of 19 oropharyngeal tularemia cases (19). Lymph node suppuration is the most common complication of oropharyngeal tularemia. Delayed initiation of tularemia treatment increases the likelihood of developing suppuration, if the treatment is not started in a few days delays may occur, and suppuration may progress despite effective treatment $(20,21)$. In a tularemia case series in Turkey, suppuration in the lymph nodes was observed in $40 \%$ of the cases with delayed diagnosis (> 3 weeks). It has been reported that if the treatment is started within the first three weeks of the disease, suppuration of the lymph nodes can be prevented [16]. In another study, it has been shown that early treatment increases the success chance and prevents lymph node suppuration (22).
In our study, lymph node suppuration was observed in all of the cases and surgical drainage was performed in $88 \%$ of the cases. This was associated with the fact that the cases in our study are comprised of those who previously received therapy with the diagnosis of pharyngitis or tonsillitis, who remained undiagnosed for a long period of time, and those who were admitted to the tertiary healthcare facility after being admitted to several primary or secondary healthcare facilities.

In biochemical tests of patients, leukocyte count, erythrocyte sedimentation rate, and C-reactive protein (CRP) levels were not found to be related to disease diagnosis or disease course. The tube agglutination test was used as a diagnostic test. Although several tests can be used for serologic diagnosis, microagglutination test is still the most widely used method (23). Although there are authors who claim that while agglutination assays are useful for early and specific diagnosis of tularemia, they may fail to detect antibodies late period on life; there are also those who state that these assays have a high reliability $(23,24)$. In the study by Bevanger et al., seropositivity was found in $64 \%$ of cases in microagglutination tests performed eight years after tularemia treatment (25). Test results of our cases were observed at a rate between $1 / 160$ and $1 / 1280$.

Natural resistance against aminoglycosides, tetracyclines, chloramphenicol and quinolones in F. tularensis strains has not been reported. Streptomycinand tetracycline-resistant strains have been developed for experimental purposes.

Erythromycin resistance is widespread in northern Europe (especially Scandinavia), in the endemic regions of Russia, and in Turkey $(14,26,27)$. It was reported that erythromycin resistance could be used as an epidemiological indicator $(2,28)$.

Doxycycline, streptomycin and quinolone preparations have been used as a monotherapy or combination therapy in the treatment of our cases. Response to treatment was achieved in $41 \%$ of the cases with the first-line therapy, while $59 \%$ of the patients required rearrangement of the treatment. Response to treatment was achieved in all cases with quinolone-containing regimens. No treatment failure was observed in patients using quinolones as a monotherapy or as a part of the combination therapy. In the study by Kılıç et al. (7). comparing treatment options in tularemia, similar results were obtained in the group treated with quinolones compared to the group treated with aminoglycosides in terms of treatment failure and relapse, whereas the failure and relapse rates were lower than in the doxycycline group. In the study in which $39 \mathrm{~F}$. tularensis strains were evaluated by E-test method; MIC values for aminoglycoside, tetracycline, fluoroquinolone, 
macrolide, penicillin, cephalosporin, imipenem, clindamycin, linezolid, chloramphenicol and rifampicin were examined. All strains were susceptible to conventional antibiotics commonly used in tularemia treatment. Fluoroquinolones were found to have the lowest MIC (50) and MIC (90) values. The lowest MIC values were emphasized in terms of their advantages compared to aminoglycosides due to oral use and lower toxicity, and it was emphasized that quinolones have the potential to be an effective firstline treatment for tularemia (29).

In a study where 145 tularemia cases were evaluated, treatment failure was reported in $38 \%$ of the cases and the most successful results were reported in the quinolone group, whereas moxifloxacin and ciprofloxacin were reported as new alternative agents in the treatment of oropharyngeal tularemia (30).

In a study in which 1034 cases were evaluated, 48\% of the cases did not respond to first-line therapy, and response was achieved with modifications in the treatments and treatment courses of 2-6 weeks. In the Gölcük epidemic, it was found that when the treatment was started after the 14th day, the clinical failure rate doubled and the recovery time was three times longer than in patients receiving early treatment (31). In the study by Çelebi et al., it was reported that doxycycline, fluoroquinolone, streptomycin, or combination therapies are administered to cases in a tularemia epidemics, and suppuration of lymphadenopathies or surgical excision were considered to be a treatment failure (14).

The cases in this study were patients who presented to our clinic long after the disease onset, complicated with suppurative lymphadenopathy, some of which failed in first-line treatment and were later treated with alternative options or combined treatments. The majority of the cases required surgical drainage.

Tularemia is a disease characterized by granulomatous, suppurative lymphadenitis and focal caseous necrosis. In our cases, similar findings were obtained in the histopathological examination. In a series in which 17 cases of lymph node resection were evaluated, granulomas, necrosis, and suppurative inflammation extending to extracapsular regions, epithelial histiocytes and rare phagocytosed bacilluslike microorganisms were observed in histopathology (30).

The diagnosis of tularemia is often delayed. It is highly important that tularemia should be considered in differential diagnosis. Delayed diagnosis is accepted as the most important factor leading to the development of complications. As it is understood from our study and other studies, the types and duration of treatment can vary and differences can be observed in cases that are past the acute stage. In our case series, treatment success was achieved with surgical treatment, treatment changes, and combined regimens with average treatment duration of 4 weeks in patients who presented in the late period 3 months after symptom onset.

In line with other studies, treatment success is higher with quinolones and quinolone-based combination therapies. Although the guideline has included a classical treatment approach for the tularemia, there is no standard approach to cases with delayed diagnosis, complicated cases and those refractory to conventional regimens.

\section{Conclusion}

These observations and other examinations have raised the question whether the chronic form of tularemia should be defined, and whether the treatment options and durations should be restandardized according to the 'chronic tularemia' definition as a 'chronic granulomatous disease'. Further studies are required on a larger number of cases on this subject.

\section{Acknowledgments, Funding: None}

Conflict of Interest: The authors declare no potential conflicts of interest with respect to the research, authorship, and/or publication of this article.

Author's Contributions: YA: Research concept and design; data collecting, analysis and interpretation of data. All authors approved the final version of the manuscript,

Ethical issues: All Authors declare that Originality of research/article etc... and ethical approval of research, and responsibilities of research against local ethics commission are under the Authors responsibilities. The study was conducted due to defined rules by the Local Ethics Commission guidelines and audits.

\section{References}

1. Petersen JM, Mead PS, Schriefer ME. Francisella tularensis: an arthropod-borne pathogen. Vet Res. 2009;40(2):07.

2. Ellis J, Oyston PC, Green M, Titball RW. Tularemia. Clin Microbiol Rev. 2002; 15(4): 631-46.

3. Berger S. Tularemia: Global Status: 2017 edition. Global Infectious Disease and Epidemiology Network (GIDEON). http://www.gideononline.com.

4. Sjöstedt A. Tularemia: history, epidemiology, pathogen physiology, and clinical manifestations. Ann N Y Acad Sci. 2007;1105:1-29.

5. Maurin M. New anti-infective strategies for treatment of tularemia. Front Cell Infect Microbiol. 2014; 4: 115.

6. Penn RL. Francisella tularensis (Tularemia) In: Mandell GL, Bennett JE, Dolin R, editors. Mandell, Douglas and Bennett's principles and practice of infectious diseases. 4th ed. New York: Churchill Ligingstone; 1995. 2060-2068.

7. Kilic S, Yesilyurt M. Tularemi: Güncel Tedavi Seçeneklerine Genel Bir Bakış Tularemia: A General Overview on Current Treatment Options. Klimik Dergisi 2011;24(1): 2-10. 
8. Tärnvik A, Berglund L. Tularemia. Eur Respir J. 2003; 21(2): 361-73.

9. WHO Guidelines on Tularaemia [İnternet]. Geneva: World Health Organization. http://www.who.int/csr/resources/publications/WHO_CDS_E PR_2007_7.pdf.

10. Tärnvik A, Sandström G, Sjöstedt A. Infrequent manifestations of tularaemia in Sweden. Scand J Infect Dis. 1997;29:443-6.

11. Tärnvik A, Chu MC. New approaches to diagnosis and therapy of tularemia. Ann N Y Acad Sci. 2007; 1105: 378 404.

12. Sahin M, Atabay HI, Bicakci Z, Unver A, Otlu S. Outbreaks of tularemia in Turkey. Kobe J Med Sci. 2007;53:37-42.

13. Ozdemir D, Sencan I, Annakkaya AN, Karadenizli A, Guclu E, Sert E, Emeksiz M, Kafali A. Comparison of the 2000 and 2005 outbreaks of tularemia in the Duzce region of Turkey. Jpn J Enfect Dis. 2007;60:51-2.

14. Celebi G, Baruonu F, Ayoglu F, Cinar F, Karadenizli A, Ugur MB, Gedikoğlu S. Tularemia, a reemerging disease in northwest Turkey: epidemiological investigation and evaluation of treatment responses. Jpn $\mathrm{J}$ Infect Dis. 2006;59:229-34.

15. Meric M, Sayan M, Willke A, Gedikoglu S. Su kaynaklı küçük bir tularemi salgını. Mikrobiyol Bul. 2008;42:49-59.

16. Helvaci S, Gedikoglu S, Akalin H, Oral B. Tularemia in Bursa, Turkey: 205 cases in ten years. Eur J Epidemiol. 2000;16:271-6.

17. Erdem H, Engin DO, Yesilyurt M, Karabay O, Elaldi N, Celebi G, Korkmaz N, Guven T, Sumer S, Tulek N, et al. Evaluation of tularaemia courses: a multicentre study from Turkey Clin Microbiol Infect. 2014;20:1042-1051.

18. Tezer MS, Ovet G, Alatas N , Gorgulu MH, Koç E , Ozturk MA. Clinical Manifestations of 16 Oropharyngeal Tularemia Patients: Experience Of A Referral Hospital In The City Of Konya, Turkey. Turk J Med Sci. 2013;43:227-23.

19. Sencan I, Sahin I, Kaya D, Oksuz S,Ozdemir D, Karabay O. An Outbreak of Oropharyngeal Tularemia with Cervical Adenopathy Predominantly in the Left Side. Yonsei Med J. 2009 Feb 28;50(1):50-54.

20. Jacobs RF. Fauci AS, Braunwald F, Isselbach RJ, Wilson JD, Martin JB, Kasper DL. Harrison's principles of internal medicine. New York: Mc Graw-Hill; 1998. Tularemia; pp. 971-975.
21. Syrjälä $H$, Schildt $R$, Räisäinen $S$. In vitro susceptibility of Francisella tularensis to fluoroquinolones and treatment of tularemia with norfloxacin and ciprofloxacin. Eur J Clin Microbiol Infect Dis. 1991 Feb; 10(2):68-70.

22. Dikici N, Ural O, Sumer S, Ozturk K. Konya bölgesinde tularemia. Mikrobiyol Bul. 2012;46:225-35.

23. Bevanger L, Maeland JA, Naess AI. Agglutinins and antibodies to Francisella tularensis outer membrane antigens in the early diagnosis of disease during an outbreak of tularemia. J Clin Microbiol. 1988; 26: 433-7.

24. Schmitt P, Splettstosser W, Porsch-Ozcurumez M, Finke EJ, Grunow R. A novel screening ELISA and a confirmatory Western blot useful for diagnosis and epidemiological studies of tularemia. Epidemiol Infect. 2005; 133:759-66.

25. Bevanger L, Maeland JA, Kvan AI. Comparative analysis of antibodies to Francisella tularensis antigens during the acute phase of tularemia and eight years later. Clin Diagn Lab Immunol. 1994;1:238-40

26. Ikäheimo I, Syrjälä H, Karhukorpi J, Schildt R, Koskela M. In vitro antibiotic susceptibility of Francisella tularensis isolated from humans and animals. J Antimicrob Chemother. 2000; 46(2): 287-90.

27. García del Blanco N, Gutiérrez Martín CB, de la Puente Redondo VA, Rodríguez Ferri EF. In vitro susceptibility of field isolates of Francisella tularensis subsp. holarctica recovered in Spain to several antimicrobial agents. Res Vet Sci. 2004; 76(3): 195-8.

28. U.S.Department of Health and Human Services, Public Health Service, Centers for Disease Control and Prevention. Biosafety in Microbiological and Biomedical Laboratories, 1999, 4th ed. U.S. Government Printing Office, Washington

29. Yesilyurt M, Kiliç S, Celebi B, Celik M, Gül S, Erdogan F, Ozel G. Antimicrobial susceptibilities of Francisella tularensis subsp. holarctica strains isolated from humans in the Central Anatolia region of Turkey. J Antimicrob Chemother. 2011 Nov;66(11):2588-92.

30. Meric M, Willke A, Finke EJ, Grunow R, Sayan M, Erdogan S, Gedikoglu S. Evaluation of clinical, laboratory, and therapeutic features of 145 tularemia cases: the role of quinolones in oropharyngeal tularemia. APMIS. 2008; 116(1): 66-73.

31. Tuncer E, Onal B, Simsek G, Elagoz S, Sahpaz A, Kilic S, Altuntas EE, Ulu Kilic A. Tularemia: potential role of cytopathology in differential diagnosis of cervical lymphadenitis: multicenter experience in 53 cases and literature review. APMIS. 2014 Mar;122(3):236-42. 